\title{
Impact of Fixed Cameras on Traffic Crashes
}

\author{
Hashem R. Al-Masaeid ${ }^{1 *}$, Randa O. Mujalli ${ }^{2}$, Esra'a H. Al-Haj ${ }^{1}$ \\ ${ }^{1}$ Civil Engineering Department, Jordan University of Science and Technology, Irbid, Jordan \\ ${ }^{2}$ Civil Engineering Department, Hashemite University, Zarqa, Jordan
}

DOI: $10.36348 /$ sjee.2020.v04i10.001

| Received: 17.12.2020 | Accepted: 26.12.2020 | Published: 30.12.2020

*Corresponding author: Hashem R. Al-Masaeid

\section{Abstract}

Speeding is one of the main causes of traffic crash fatalities. Different effective strategies have been applied to prevent this critical issue; for example, humps, setting speed limit, and speed cameras. This study evaluates the effectiveness of speed cameras that are implemented on midblock of urban, suburban and on segments of rural arterials in Jordan in January 2018. Interrupted time series analysis (ARIMA model) was used for examining the effects of the speed cameras on the number of crashes. Various functions; including linear, quadratic, logarithmic, exponential, and power, were applied in order to evaluate the effect of speed cameras on traffic crashes. Results of analyses indicated that speed cameras implemented on suburban and urban arterials with speed limit less than $80 \mathrm{~km} / \mathrm{h}$ had a crash reduction of 10 to $19 \%$. On the contrary, it was found that the number of crashes on a limited number of rural arterials' segments was increased by about $36 \%$, this result should be further investigated since the sample size of rural segments was relatively small.

Keywords: Traffic crashes, fixed cameras, safety evaluation, time series, arterials.

Copyright ( 2020 The Author(s): This is an open-access article distributed under the terms of the Creative Commons Attribution 4.0 International License (CC BY-NC 4.0) which permits unrestricted use, distribution, and reproduction in any medium for non-commercial use provided the original author and source are credited.

\section{INTRODUCTION}

Speed has been considered as the main risk factor in road traffic injuries, causing most casualties in traffic crashes. In developed countries, $30 \%$ of fatalities on roads result from speeding crashes. In Jordan, about $35 \%$ of road crash casualties are attributed to traffic speeding [1]. While in developing countries, speeding is considered the main cause of half of all road crashes [2].

Various measures were used to reduce speeding such as roads humps, setting speed limits and speed cameras. However, speed cameras are considered to be a very cost-effective method of controlling vehicle speed to reduce road crashes [2]. Many countries around the world have used this technology to reduce crashes. An automated traffic enforcement system is a mechanical recording device that is triggered automatically when a traffic violation is committed, and record the vehicle and driver related information. This allows the information about the violating vehicle to be recorded. After the recorded data is processed the vehicle and the driver can be easily identified and appropriate tickets can be issued to them [3].

In Jordan, a very limited number of traffic speed cameras were installed before 2014. In 2018 and
2019, however, 113 fixed speed cameras were installed on midblock of roads and roads intersections. The fixed speed camera uses radar technology to detect speeding vehicles, and covers about $50 \mathrm{~m}$ away from the speed camera, and it can detect the violation vehicles by taking a picture for the plate number. Such cameras register the location, time, type of violating vehicles and their speeds. Furthermore, it can record the speeds for more than one vehicle at the same time. The fixed speed cameras that are located on midblock of roads only issue speeding tickets.

The objective of this study is to evaluate the effectiveness of the implemented speed cameras on reducing traffic crashes. The performance of traffic speed cameras installed in 2018 will be investigated in the study. Interrupted time series approach was adopted in this research due to its ability to account for the autocorrelation, trend and the seasonality that might exist in the data selected for this research.

\section{BACKGROUND}

Several studies have shown that applying speed cameras can reduce fatal and injury crashes on both urban and rural roads. On urban roads, studies revealed that speed cameras are effective in reducing all types of collisions, including fatal, injury, and property 
damage only [4, 5]. Also, it was found that speed cameras installed on rural roads had resulted in crash reductions from 20 to $25 \%[6,7]$. Using interrupted time series analysis, Carnis and Blais [8] evaluated the safety impact of speed cameras, and they showed that the rate of injuries and fatalities per 100,000 vehicles per month decreased by $7.3 \%$ and $20.7 \%$, respectively.

On the other hand, some studies focused on the effect of speed camera range at different distances from the camera site, using 250, 500, and $1000 \mathrm{~m}$. And they reported that as the distance from the camera decreases, the number of fatal and injury crashes decreases and the most effective reduction in crashes was found within 200-250 $\mathrm{m}$ from speed camera site [9-11]. They also recommended the use of $500 \mathrm{~m}$ before and $500 \mathrm{~m}$ after the camera site as the area of influence [12,13].

From methodological perspective, several evaluation methods are used to investigate the safety impact of the implemented crash countermeasures. These methods include before-and-after with control group, regression, and interrupted time series analyses, among other probabilistic methods [14, 15]. Although before-and-after with control group method is sound and provides legitimate results, sometimes it is difficult to find similar sites as control group. Regression analyses such as linear, Poisson, and Negative Binomial are used to investigate the impact of certain factors on crashes, and these analyses are suitable for crosssectional data. Finally, the interrupted time series analysis is suitable to model crash data and to evaluate the safety impact of an implemented measure [16, 17]. It does not need an equal before and after periods and may help the evaluator to use different time scales in the analysis.

\section{METHODOLOGY AND DATA COLLECTION}

At the start of January 2018, the Greater Amman Municipality (GAM) installed twenty four speed cameras on the midblock of urban, suburban, and Amman-Queen Alia Air-port arterials. The exact locations of the installed cameras, according to the GPS coordinates, were obtained from the GAM. While, the crash data along $500 \mathrm{~m}$ before each camera and $500 \mathrm{~m}$ after the camera were acquired from Jordan Public Security Directorate (PSD). The crash dataset covers the period from January 2014 to June 2018; four years before and one year and half after the installation of speed cameras. According to the speed limit, the twenty-four midblock arterials were categorized into four groups, as shown in Table-1.

Table-1: Characteristics of the investigated midblock speed cameras sites

\begin{tabular}{|l|l|l|l|l|l|}
\hline $\begin{array}{l}\text { Group } \\
\text { number }\end{array}$ & $\begin{array}{l}\text { Number of } \\
\text { midblock } \\
\text { arterials }\end{array}$ & $\begin{array}{l}\text { Number of crashes } \\
\text { (Jan 2014-Dec 2017) }\end{array}$ & $\begin{array}{l}\text { Number of crashes } \\
\text { (Jan 2018-Jun } \\
\mathbf{2 0 1 9 )}\end{array}$ & $\begin{array}{l}\text { Speed } \\
\text { limit }\end{array}$ & Road characteristics \\
\hline $\mathbf{1}$ & 3 & 1525 & 644 & $\begin{array}{l}90- \\
100 \mathrm{~km} / \mathrm{h}\end{array}$ & $\begin{array}{l}\text { Rural/ two way /four } \\
\text { lane/divided }\end{array}$ \\
\hline $\mathbf{2}$ & 11 & 2177 & 1066 & $80 \mathrm{~km} / \mathrm{h}$ & $\begin{array}{l}\text { Suburban/two } \\
\text { way/divided }\end{array}$ \\
\hline $\mathbf{3}$ & 5 & 2250 & 1023 & $70 \mathrm{~km} / \mathrm{h}$ & $\begin{array}{l}\text { suburban/two } \\
\text { way/four lane/divided }\end{array}$ \\
\hline $\mathbf{4}$ & 5 & 2789 & 1312 & $60 \mathrm{~km} / \mathrm{h}$ & $\begin{array}{l}\text { Urban/two way/four } \\
\text { lane/divided }\end{array}$ \\
\hline
\end{tabular}

\section{Analysis of Crash Data}

In this study, the effect of speed camera is estimated based on one dependent variable; number of crashes, and the crash data was aggregated on a monthly basis. Thus, for each site, there were 66 observations (66 months in the period from January 2014 to June 2019).

The first independent variable is the time, it is an interval variable, starts at 1 from first observation and successively increases to the last observation 66, which was considered as a control variable. The second independent variable called Intervention variable, is a binary variable (step function) and refers to the introduction of the speed camera which is coded 0 for all time points before the intervention (January 2014 to December 2017) while the time points after intervention are coded 1 (January 2018 to June 2019).This variable estimates the change in the level immediately after introducing the intervention. The third independent variable is called time after intervention variable or interaction variable, which is coded as $1,2,3 \ldots, 18$ from intervention time point (January 2018) to the last data point, and 0 for data points before the intervention (January 2014 to December 2017). This variable estimates changes in the slope of the series.

Various functions were considered for interaction variable to capture changes in the slope of the midblock arterials traffic crashes series, including linear, logarithmic, quadratic, power and exponential $[18,8]$.

The data were analyzed using interrupted time series, autoregressive integrated moving average (ARIMA Model) [19, 20]. Due to the limited traffic crashes data which was found for arterials where speed cameras are installed, the interrupted time series has been considered a valuable technique for evaluating the effectiveness of intervention that is introduced at 
specific time [21, 22]. The hypothetical scenario considers that the intervention was not introduced and the trend does not change, that is called "counterfactual"; expected trend when the intervention does not exist given the preexisting trend [22, 21]. The strength of the interrupted time series is the ability to account for the autocorrelation, trend, and seasonality that might exist in the data. Sufficient number of data points before and after the intervention is required when conducting interrupted time series analysis. In general, 12 data points before and after the intervention was recommended $[20,22,23]$. In this study, 48 observations before the intervention and 18 observations after the intervention were used.

Box and Jenkins [19] provided a methodology that includes three stages: identification estimation, and diagnostic. At identification stage, two methods are used to investigate the stationarity of time series; visual inspection of autocorrelation functions plot (ACF) and partial autocorrelation function plot (PACF) and by using the statistical test, Augmented Dickey Fuller. After that, in estimation stage, the parameter of ARIMA Model ( $p$ and $q$ ) is estimated by conditional sum of squares method where several ARIMA Models were estimated and the best model was chosen based on Akike's Information Criterion (AIC). A diagnostic stage is performed to assess the ARIMA model adequacy by examining the presence of autocorrelation in the residuals by Ljung-Box test.

When the ARIMA model is determined, the independent variables are introduced; different functions were applied for the "time after intervention" variable. The equations of intervention analysis are assessed by using mean absolute percentage error (MAPE) where the model with least MAPE is the best. $\mathrm{R}$ statistical software, version 4.0.0 was used to conduct this study. Figure-1 illustrates and summarizes the methodology that is used in this research.

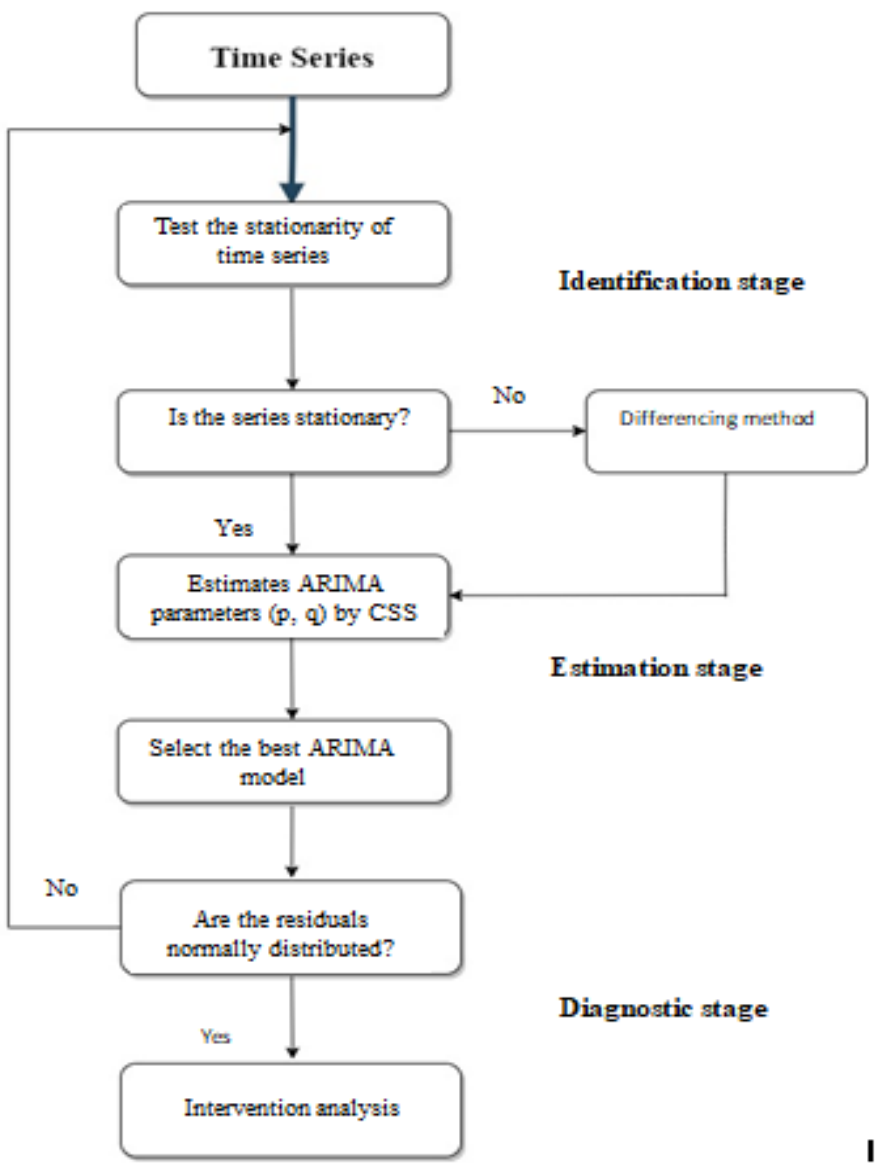

Fig-1: Methodology of Interrupted time series (ITS)

\section{Result of Interrupted Time Series Analysis}

Some segments of Amman-Queen Alia Airport road are considered rural arterials and only three cameras were installed along this arterial. Table-2 shows the effect of speed cameras on the roads 'groups 1'. The linear and logarithmic models indicate that the intervention variable has a positive sign, $(6.225$; $\mathrm{p}<$ $0.05,4.87 ; \mathrm{p}<0.05$ ), which implies a significant increase in the number of crashes immediately after introduction of the speed cameras. Furthermore, the time after intervention variable indicates that the speed cameras are associated with a non-significant decrease in number of crashes in all five models. The moving average parameter estimate, labeled Ma1 as shown in Table-2, is 0.246 and has a significant $t$-value. 
Table-2: Effects of speed cameras on the number of crashes on Amman Air-port segments

\begin{tabular}{|c|c|c|c|c|c|c|c|c|c|c|}
\hline \multicolumn{11}{|c|}{ Group (1), ARIMA model $(0,0,1)$} \\
\hline \multicolumn{11}{|c|}{$\begin{array}{l}\text { AIC }=400.14 \\
Q^{*}=2.449 \text { p-value }=0.9916\end{array}$} \\
\hline & \multicolumn{2}{|l|}{ Linear } & \multicolumn{2}{|c|}{ Quadratic } & \multicolumn{2}{|c|}{ logarithmic } & \multicolumn{2}{|l|}{ power } & \multicolumn{2}{|c|}{ exponential } \\
\hline & $\mathrm{B}$ & S.E. & $\beta$ & S.E. & $\mathrm{B}$ & S.E. & $\mathrm{B}$ & S.E. & $\mathrm{B}$ & S.E. \\
\hline Ma1 & 0.246 & 0.125 & 0.246 & 0.125 & 0.246 & 0.125 & 0.246 & 0.125 & 0.246 & 0.125 \\
\hline Intercept & 11.990 & 1.315 & 11.63 & 2.021 & 10.09 & 2.262 & 2.327 & 0.143 & 2.451 & $\mathbf{0 . 0 8 3}$ \\
\hline Time & 0.093 & 0.046 & $\begin{array}{ll}0.135 \\
-0.008 \\
\end{array}$ & $\begin{array}{l}\mathbf{0 . 1 9 0} \\
\mathbf{0 . 0 0 3} \\
\end{array}$ & 1.425 & 0.739 & 0.098 & 0.047 & 0.006 & 0.002 \\
\hline Intervention & 6.225 & 2.366 & 4.296 & 2.780 & 4.870 & 2.407 & 0.219 & 0.153 & 0.156 & 0.161 \\
\hline Time after intervention & -0.2 & 0.209 & -0.327 & 0.324 & -0.316 & 0.204 & -0.012 & 0.013 & -0.017 & 0.013 \\
\hline MAPE & \multicolumn{2}{|l|}{24.916} & \multicolumn{2}{|l|}{24.92} & \multicolumn{2}{|l|}{25.068} & \multicolumn{2}{|l|}{8.815} & \multicolumn{2}{|l|}{8.768} \\
\hline $\begin{array}{l}\mathrm{Q}^{*} \\
\mathrm{P} \text {-value }\end{array}$ & \multicolumn{2}{|l|}{$\begin{array}{l}6.129 \\
0.726\end{array}$} & \multicolumn{2}{|l|}{$\begin{array}{l}6.286 \\
0.615\end{array}$} & \multicolumn{2}{|l|}{$\begin{array}{l}6.1755 \\
0.722\end{array}$} & \multicolumn{2}{|l|}{$\begin{array}{l}4.725 \\
0.05\end{array}$} & \multicolumn{2}{|l|}{$\begin{array}{l}4.826 \\
0.049\end{array}$} \\
\hline
\end{tabular}

Note: Bold values denote statistical significance at the $\mathrm{p}<0.05$ level.

Table-3 illustrates the effect of speed cameras in reducing crashes on suburban mid-block roads with speed limit $80 \mathrm{~km} / \mathrm{h}$ ' group 2'. The positive coefficients of time after intervention $(1.738 ; \mathrm{p}<0.05,0.003 ; \mathrm{p}<$
$0.05)$ in the quadratic and power models suggest that the number of crashes increases through the enforcement period.

Table-3: Effects of speed cameras on the number of crashes on suburban arterials

\begin{tabular}{|c|c|c|c|c|c|c|c|c|c|c|}
\hline \multicolumn{11}{|c|}{ Group (2) ARIMA model $(0,1,1)$} \\
\hline \multicolumn{11}{|c|}{$\mathrm{AIC}=523.57$} \\
\hline \multicolumn{11}{|c|}{$Q^{*}=7.6889, p$-value $=0.7409$} \\
\hline & \multicolumn{2}{|l|}{ Linear } & \multicolumn{2}{|c|}{ Quadratic } & \multicolumn{2}{|c|}{ logarithmic } & \multicolumn{2}{|l|}{ power } & \multicolumn{2}{|c|}{ exponential } \\
\hline & $\mathrm{B}$ & S.E. & $\beta$ & S.E. & $\beta$ & S.E. & $\mathrm{B}$ & S.E. & $\beta$ & S.E. \\
\hline Ma1 & -0.718 & 0.090 & -0.718 & 0.090 & -0.718 & 0.090 & -0.718 & 0.090 & -0.718 & 0.090 \\
\hline Intercept & 25.109 & 3.588 & 12.44 & 5.120 & - & - & 2.450 & 0.129 & 3.038 & 0.204 \\
\hline Time & 0.868 & 0.127 & $\begin{array}{l}2.387 \\
-0.031 \\
\end{array}$ & $\begin{array}{l}0.481 \\
0.009 \\
\end{array}$ & 15.72 & 0.550 & 0.44 & 0.042 & 0.025 & 0.006 \\
\hline Intervention & -10.52 & 10.37 & -4.943 & 7.045 & -8.415 & 6.124 & -0.214 & 0.137 & -0.226 & 0.220 \\
\hline Time after intervention & 0.602 & 1.09 & 1.738 & 0.821 & 0.285 & 0.530 & 0.003 & 0.011 & 0.020 & 0.021 \\
\hline MAPE & \multicolumn{2}{|l|}{25.781} & \multicolumn{2}{|l|}{22.132} & \multicolumn{2}{|l|}{23.184} & \multicolumn{2}{|l|}{5.656} & \multicolumn{2}{|l|}{6.35} \\
\hline $\begin{array}{l}\mathrm{Q}^{*} \\
\mathrm{P} \text {-value }\end{array}$ & \multicolumn{2}{|l|}{$\begin{array}{l}7.688 \\
0.740\end{array}$} & \multicolumn{2}{|l|}{$\begin{array}{l}10.482 \\
0.232\end{array}$} & \multicolumn{2}{|l|}{$\begin{array}{l}13.86 \\
0.179\end{array}$} & \multicolumn{2}{|l|}{$\begin{array}{l}12.921 \\
0.166\end{array}$} & \multicolumn{2}{|l|}{$\begin{array}{l}10.193 \\
0.116\end{array}$} \\
\hline
\end{tabular}

Note: Bold values denote statistical significance at the $\mathrm{p}<0.05$ level.

For speed cameras installed on urban arterials with speed limit of $70 \mathrm{~km} / \mathrm{h}$., the linear model in Table4 shows the negative coefficient for the intervention term $(b=-13.27 ; p<0.05)$, which indicates a significant decline in the number of crashes immediately after the installation of the speed cameras. Whereas, at the long term, the positive coefficient for the time after intervention $(\mathrm{B}=0.907 ; \mathrm{p}<0.05)$ in the logarithmic model indicates that the effect of the speed cameras diminishes through the enforcement period. The seasonal autoregressive parameter estimate, labeled Sar 1 , is 0.360 , and has a significant $t$-value.

Table-4: Effect of speed cameras on crashes of suburban arterials (speed limit $70 \mathrm{~km} / \mathrm{h}$ )

\begin{tabular}{|c|c|c|c|c|c|c|c|c|c|c|}
\hline \multicolumn{11}{|c|}{ Group (3), ARIMA model $(0,1,1)(1,0,0)[12]$} \\
\hline \multicolumn{11}{|c|}{$\mathrm{AIC}=543.72$} \\
\hline \multicolumn{11}{|c|}{$\mathrm{Q}^{*}=9.9039, \mathrm{p}$-value $=0.449$} \\
\hline & \multicolumn{2}{|l|}{ Linear } & \multicolumn{2}{|c|}{ Quadratic } & \multicolumn{2}{|c|}{ Logarithmic } & \multicolumn{2}{|l|}{ power } & \multicolumn{2}{|c|}{ Exponential } \\
\hline & $\mathrm{B}$ & S.E. & $\mathrm{B}$ & S.E. & $\mathrm{B}$ & S.E. & $\mathrm{B}$ & S.E. & $\beta$ & S.E. \\
\hline Ma1 & -0.830 & 0.092 & -0.830 & 0.092 & -0.830 & 0.092 & -0.83 & 0.092 & -0.83 & 0.092 \\
\hline Sar1 & 0.360 & 0.121 & 0.360 & 0.121 & 0.360 & 0.121 & 0.360 & 0.121 & 0.36 & 0.121 \\
\hline Intercept & 30.442 & 4.629 & 27.021 & 6.115 & 16.856 & 7.205 & 2.986 & 0.157 & 3.34 & 0.103 \\
\hline Time & 0.636 & 0.154 & $\begin{array}{l}1.07 \\
-0.008 \\
\end{array}$ & $\begin{array}{l}0.545 \\
0.010 \\
\end{array}$ & 10.107 & 2.330 & 0.263 & 0.050 & 0.016 & 0.003 \\
\hline Intervention & -13.27 & 6.673 & -11.16 & 7.133 & -9.303 & 6.390 & -0.15 & 0.134 & -0.23 & 0.143 \\
\hline Time after intervention & 0.419 & 0.566 & 1.004 & 0.898 & 0.906 & 0.538 & 0.012 & 0.011 & -.002 & 0.012 \\
\hline MAPE & \multicolumn{2}{|l|}{25.07} & \multicolumn{2}{|l|}{25.4} & \multicolumn{2}{|l|}{25.234} & \multicolumn{2}{|l|}{5.999} & \multicolumn{2}{|l|}{6.159} \\
\hline $\begin{array}{l}\mathrm{Q}^{*} \\
\mathrm{P} \text {-value }\end{array}$ & \multicolumn{2}{|l|}{$\begin{array}{l}9.3685 \\
0.3122\end{array}$} & \multicolumn{2}{|l|}{$\begin{array}{l}11.05 \\
0.13\end{array}$} & \multicolumn{2}{|l|}{$\begin{array}{l}13.908 \\
0.0842\end{array}$} & \multicolumn{2}{|c|}{$\begin{array}{l}17.249 \\
0.0276\end{array}$} & \multicolumn{2}{|l|}{$\begin{array}{l}10.348 \\
0.024\end{array}$} \\
\hline
\end{tabular}


Finally, Table-5 shows the effect of speed cameras installed on midblock of urban roads 'group 4'. In all models, the negative coefficient for the time after intervention variable suggests that there is a significant decline in the number of crashes, in other words, at the long term the speed cameras have yielded a valuable effect in reducing the number of crashes. The moving average parameter estimate is -0.7624 and has the nonsignificant t-value.

Table-5: Effects of speed cameras on the number of crashes on urban roads

\begin{tabular}{|c|c|c|c|c|c|c|c|c|c|c|}
\hline \multicolumn{11}{|c|}{ Group (4), ARIMA Model $(0,1,1)$} \\
\hline \multicolumn{11}{|c|}{$\mathrm{AIC}=538.4$} \\
\hline \multicolumn{11}{|c|}{$\mathrm{Q}^{*}=11.581 \mathrm{p}$-value $=0.396$} \\
\hline & \multicolumn{2}{|l|}{ Linear } & \multicolumn{2}{|c|}{ Quadratic } & \multicolumn{2}{|c|}{ logarithmic } & \multicolumn{2}{|l|}{ Power } & \multicolumn{2}{|c|}{ Exponential } \\
\hline & $\beta$ & S.E. & $\mathrm{B}$ & S.E. & $\mathrm{B}$ & S.E. & $\beta$ & S.E. & $\beta$ & S.E. \\
\hline Ma1 & -0.762 & 0.088 & -0.762 & 0.088 & -0.762 & 0.088 & -0.762 & 0.088 & -0.76 & 0.088 \\
\hline Intercept & 34.46 & 3.78 & 31.707 & 5.800 & 15.54 & 6.656 & 3.125 & 0.117 & 3.535 & 0.068 \\
\hline Time & 0.936 & 0.13 & $\begin{array}{l}1.267 \\
-0.006\end{array}$ & $\begin{array}{l}0.545 \\
0.010\end{array}$ & 14.28 & 2.175 & 0.295 & 0.038 & 0.018 & 0.002 \\
\hline Intervention & -3.96 & 7.33 & -1.955 & 7.980 & 4.466 & 7.085 & 0.037 & 0.125 & -0.11 & 0.133 \\
\hline Time after intervention & -1.267 & 0.60 & -0.821 & 0.930 & -0.579 & 0.601 & -0.009 & 0.010 & -0.022 & 0.010 \\
\hline MAPE & \multicolumn{2}{|c|}{19.49804} & \multicolumn{2}{|c|}{19.26706} & \multicolumn{2}{|l|}{20.637} & \multicolumn{2}{|l|}{6.4} & \multicolumn{2}{|l|}{4.77} \\
\hline $\begin{array}{l}\mathrm{Q}^{*} \\
\mathrm{P} \text { value }\end{array}$ & \multicolumn{2}{|c|}{15.571} & \multicolumn{2}{|c|}{$\begin{array}{l}14.907 \\
0.0609\end{array}$} & \multicolumn{2}{|l|}{$\begin{array}{l}11.177 \\
0.263\end{array}$} & \multicolumn{2}{|l|}{$\begin{array}{l}15.564 \\
0.037\end{array}$} & \multicolumn{2}{|l|}{$\begin{array}{l}17.441 \\
0.04\end{array}$} \\
\hline
\end{tabular}

It is worth mentioning that the power and exponential models were excluded in groups 1,3 , and 4 ; the p-value of ljung- box test is less than 0.05 ; therefore, reject the null hypothesis that the residuals are uncorrelated, which indicating that the residuals of these models are not normally distributed and exhibits lack of fits.

Mean absolute percentage error (MAPE) was used as goodness of fit measures, as shown in Table-6, the models have the least MAPE were considered the most robust and used to compute the number of crashes were prevented or increased per month and for the whole enforcement period. The non-significant variables were not used in the computation. According to results presented in Table-7, on urban and suburban roads with speed limit $70 \mathrm{~km} / \mathrm{h}$, the speed cameras were associated with $10 \%$ and $19 \%$ decrease in the number of crashes, respectively. In other words, 8 and 13 crashes were avoided on monthly averages. A total of 140 and 239 traffic crashes were reduced during 18 months period. Based on estimates from the power model in Table 3, negligible effect was observed on the suburban roads that have speed limit of $80 \mathrm{~km} / \mathrm{h} ; 0.6 \%$ increase in the number of crashes due to installation of speed cameras. On the Contrary, on the Air-port road, the installed speed camera was associated with a $36.29 \%$ increase in the number of crashes, which is equivalent to an increase of 6 crashes per month (a total of 113 for 18 months period).

Table-6: Selected models for all four groups (MAPE value is the least)

\begin{tabular}{|l|l|l|}
\hline Groups number & Selected model & MAPE \\
\hline urban roads & Quadratic & 19.267 \\
\hline Suburban roads with speed limits $70 \mathrm{~km} / \mathrm{h}$ & Linear & 25.07 \\
\hline Suburban roads with speed limits $80 \mathrm{~km} / \mathrm{h}$ & Power & 5.656 \\
\hline Air Port road & Linear & 24.9167 \\
\hline
\end{tabular}

Table-7: Number of crashes avoided /increased on the selected midblock arterials

\begin{tabular}{|l|l|l|l|}
\hline & $\begin{array}{l}\text { Total crashes } \\
\text { avoided /increased }\end{array}$ & $\begin{array}{l}\text { Average crashes } \\
\text { avoided per month }\end{array}$ & $\begin{array}{l}\text { Change in relative } \\
\text { percentage }\end{array}$ \\
\hline urban arterials (speed limit $60 \mathrm{~km} / \mathrm{h})$ & -140 & -8 & $-10 \%$ \\
\hline Suburban arterials (speed limit $70 \mathrm{~km} / \mathrm{h})$ & -239 & -13 & $-19 \%$ \\
\hline Suburban arterials (speed limit $80 \mathrm{~km} / \mathrm{h})$ & +2 & - & $+0.6 \%$ \\
\hline Air-Port arterial (speed limit $90-100 \mathrm{~km} / \mathrm{h})$ & \multicolumn{1}{|c|}{+113} & +6 & $+36.29 \%$ \\
\hline
\end{tabular}

\section{DISCUSSIONS}

The results of the interrupted time series analyses indicated that the installation of speed cameras had a significant impact on urban and suburban traffic crashes reduction. Between January 2018 and June 2019, the estimates suggest that about 140 and 239 crashes were prevented on urban and suburban arterials with speed limit of 60 and $70 \mathrm{~km} / \mathrm{h}$, respectively. The obtained crash reductions on urban and suburban roads were 10 and $19 \%$, respectively. These results are consistent with findings of previous studies, which indicated that speed cameras implemented on urban 
roads had crash reduction of 15 to $20 \%$ [24, 4, 12, 5]. However, results of this study revealed that speed cameras installed on suburban roads with speed limit of $80 \mathrm{~km} / \mathrm{h}$ had no effect on traffic crashes.

On the other hand, speed cameras installed on the Air-port road were associated with an increase in traffic crashes by $36.26 \%$. As stated before, the segments included in this arterial were located in rural area. This finding contradicts with cited literatures, which indicates that speed cameras are efficient in reducing crashes on rural roads [6, 13, 7]. However, studies revealed that speed cameras installed on rural roads are less efficient than those installed on urban roads [24]. In fact, in this study only three speed cameras were implemented on the Air-port road, and this small sample size is not sufficient to provide a sound and conclusive result. Thus; further studies are recommended to highlight this issue in Jordan.

It is worth mentioning that traffic volumes were not available at the sites where speed cameras are installed. However, all selected cameras were installed on major urban and suburban arterials that are subjected to high traffic volumes. In addition, the Air-Port road is considered as one of the major rural roads in the country. In Jordan, criteria to implement speed cameras at midblock sites are based on crash frequency for the three past years, proportion of speeding vehicles, and traffic volume. In the United Kingdom and United States guidelines for deploying speed cameras were commonly addressed school zones, construction zones, high crash severity and frequency, and high traffic volume and speed violations [25-28].

\section{CONCLUSIONS}

Based on the analyses carried out in this study, speed cameras installed on the midblock of urban and suburban with speed limit of 60 and $70 \mathrm{~km} / \mathrm{h}$., respectively, had an efficient reduction of crashes of 10 and $19 \%$. These results are consistent with findings in the cited literatures. However, speed cameras installed on midblock of suburban arterials with speed limit of 80 $\mathrm{km} / \mathrm{h}$ were not found to have a significant effect on decreasing traffic crashes. In contrast, speed cameras implemented on the Air-port arterial; which is considered as a rural arterial, had increased traffic crashes by about $36 \%$. In this study, the effect of only three speed cameras installed on the Air-port arterial was evaluated; therefore, further studies are recommended to obtain a conclusive result.

\section{REFERENCES}

1. Al-Masaeid, H. R. (2009). Traffic a accidents in Jordan. Jordan Journal of Civil Engineering, 3(4): 331-343.

2. World Health Organization. (2017). Road Safety: Basic Facts. [online] Available at: https://www.who.int/violence_injury_prevention/p ublications/road_traffic/Media_brief_all_factsheets _web_rev_nov_2017.pdf?ua=1 [Accessed May 2020].

3. Sagberg, F. (2000). Automatic enforcement technologies and systems. Technical Research Centre of Finland (VTT).

4. Li, R., El-Basyouny, K., \& Kim, A. (2015). Before-and-After Empirical Bayes Evaluation of Automated Mobile Speed Enforcement on Urban Arterial Roads. Transportation Research Record: Journal of the Transportation Research Board, 2516: 44-52.

5. Moon, J.-P., \& Hummer, J. E. (2010). Speed Enforcement Cameras in Charlotte, North Carolina. Transportation Research Record: Journal of the Transportation Research Board, 2182: 31-39.

6. Jones, A. P., Sauerzapf, V., \& Haynes, R. (2008). The effects of mobile speed camera introduction on road traffic crashes and casualties in a rural county of England. Journal of Safety Research, 39(1): 101-110.

7. Pérez, K., Marí-Dell'Olmo, M., Tobias, A., \& Borrell, C. (2007). Reducing Road Traffic Injuries: Effectiveness of Speed Cameras in an Urban Setting. American Journal of Public Health, 97(9): 1632-1637.

8. Carnis, L., \& Blais, E. (2013). An assessment of the safety effects of the French speed camera program. Accident Analysis \& Prevention, 51(6): 301-309.

9. Hess, S. (2004). Analysis of the Effects of Speed Limit Enforcement Cameras: Differentiation by Road Type and Catchment Area. Transportation Research Record: Journal of the Transportation Research Board, 1865: 28-34.

10. Li, H., Graham, D. J., \& Majumdar, A. (2013). The impacts of speed cameras on road accidents: An application of propensity score matching methods. Accident Analysis \& Prevention, 60(4): 148-157.

11. Mountain, L. J., Hirst, W. M., \& Maher, M. J. (2004) Costing lives or saving lives: a detailed evaluation of the impact of speed cameras. Traffic, Engineering and Control, 45(8):280-287.

12. Cunningham, C. M., Hummer, J. E., \& Moon, J. P. (2008). Analysis of Automated Speed Enforcement Cameras in Charlotte, North Carolina. Transportation Research Record: Journal of the Transportation Research Board, 2078: 127-134.

13. Novoa, A. M., Perez, K., Santamarina-Rubio, E., Mari-Dell'olmo, M., \& Tobias, A. (2010). Effectiveness of speed enforcement through fixed speed cameras: a time series study. Injury Prevention, 16 (1): 12-16.

14. Al-Masaeid, H. R., Bazlamit, S. M, Al-Zedaneen, A. E., \& Al-Mofleh, H. (2020). Impact of fasting on traffic accidents. Jordan Journal of Civil Engineering, 14(3):431-442.

15. Al-Masaeid, H. R., Obaidat, M. T., \& Gharaybeh, F. A. (1997). Pedestrian accidents along urban arterial midblocks. Journal of Traffic Medicine, 25(3-4):65-70. 
16. Newstead, S. (2009). Evaluation of the crash effects of the Queensland mobile speed camera program in the years 2006-2007. Monash University Accident Research Center.

17. Rose, S. M. S. F., Contrepois, K., Moneghetti, K. J., Zhou, W., Mishra, T., Mataraso, S., ... \& Rego, S. (2019). A longitudinal big data approach for precision health. Nature medicine, 25(5), 792-804.

18. Elvik, R. (2011). Publication bias and time-trend bias in meta-analysis of bicycle helmet efficacy: a re-analysis of Attewell, Glase and McFadden, 2001. Accident Analysis \& Prevention, 43(3), 1245-1251.

19. Box, G. E. P., Jenkins, G. M., \& Day, H. (1976). Time series analysis: forecasting and control. California: PUSA.

20. Wagner, A. K., Soumerai, S. B., Zhang, F., \& Ross-Degnan, D. (2002). Segmented regression analysis of interrupted time series studies in medication use research. Journal of Clinical Pharmacy and Therapeutics, 27(4): 299-309.

21. Penfold, R. B., \& Zhang, F. (2013). Use of Interrupted Time Series Analysis in Evaluating Health Care Quality Improvements. Academic Pediatrics, 13(6).

22. Zhang, F., Wagner, A. K., \& Ross-Degnan, D. (2011). Simulation-based power calculation for designing interrupted time series analyses of health policy interventions. Journal of Clinical Epidemiology, 64(11): 1252-1261.
23. Bonander, C., Nilson, F., \& Andersson, R. (2014). The effect of the Swedish bicycle helmet law for children: An interrupted time series study. Journal of Safety Research, 51: 15-22.

24. Pauw, E. D., Daniels, S., Brijs, T., Hermans, E., \& Wets, G. (2014). Behavioural effects of fixed speed cameras on motorways: Overall improved speed compliance or kangaroo jumps? Accident Analysis \& Prevention, 73(4):132-140.

25. National Highway Traffic Safety Administration. (2008). Speed Enforcement Program Guidelines. US Department of Transportation, Washington.

26. Transport for New South Wales. (2012). NSW Speed Camera Strategy. [online].Available at: https://www.rms.nsw.gov.au/roadsafety/downloads /nsw_speed_camera_strategy.pdf [Accessed Feb. 2020].

27. Department for Transport, United Kingdom. (2007). Use of Speed and Red Light Cameras for Traffic Enforcement: Guidance on Deployment, Visibility and Signing. [online] Available at: https://assets.publishing.service.gov.uk/government /uploads /system /uploads/ attachment_data/file/465165/dft-circular-0107.pdf [Accessed May 2020].

28. Li, H., \& Graham, D. J. (2016). Heterogeneous treatment effects of speed cameras on road safety. Accident Analysis \& Prevention, 97(6): 153-161. 